\title{
POR UNA GEO-GRAFICIDAD DE LAS RESISTENCIAS EN TERRITORIOS LIBRES DE EXTRACTIVISMO, EN DISPUTA Y DECAPITADOS: LA CUESTIÓN DE LAS POSICIONALIDADES DE LAS RESISTENCIAS CONTRA-MINERAS EN AMÉRICA LATINA ${ }^{\top}$
}

\author{
CRISTIAN ABAD RESTREPO \\ Politólogo, Magister en Hábitat \\ Estudiante de doctorado en geografía \\ Universidad Federal do Paraná - Brasil
}

\begin{abstract}
RESUMEN
El presente artículo conceptualiza sobre las posicionalidades creadas en condiciones de resistencia contra la minería moderna, a saber, minería metalífera de gran escala en América Latina, que ha marcado la experiencia y la subjetividad de los cuerpos en defensa de los territorios. Esto ha configurado un nuevo patrón de conflictividad establecido por las resistencias contra-mineras en América Latina y el Caribe mediante la constitución de tres procesos articulados y diferentes que son: el largo siglo XX que va hasta 1989 caracterizado por una resistencia desarrollada dentro de una "crítica de la modernidad-minera", un periodo de transición epistémico-político de 1990 a 1999 y el periodo iniciado entre 2000 hasta la actualidad, denominado "critica a la modernidad-minera". Dentro de esta periodización crítica de los discursos que emanan desde las diversas resistencias, se establecen tres posicionalidades que son: resistencias en territorios libres de extractivismo, resistencias en territorios en disputa y territorios decapitados en resistencia. En ese sentido, la periodización de los discursos y las posicionalidades configura lo que llamamos la geograficidad de las resistencias contra-extractivas mineras.
\end{abstract}

Palabras claves: resistencias contra-extractivas, territorio, cuerpo, posicionalidad, geograficidad, conflicto.

1. El presente artículo es uno de los resultados de la investigación, aun en desarrollo, adelantada en el doctorado en geografía realizado en la Universidad Federal de Paraná, titulada “descolonización y ampliación de las resistencias contra-extractivas en/desde América Latina/Abya Yala”. 


\begin{abstract}
The aim of this article is to conceptualize the positionality created in conditions of resistance against modern mining, which has marked the experience and subjectivity of the bodies in defense of the territories. Through these, it has been possible to unmask the trappings of mining modernity, while at the same time allowing the creation of alternative worlds to modernity, radicalizing projects and life forms with other horizons of meaning. This has configured a new conflict pattern seen in a geograficity of counter-mining resistance in Latin America and the Caribbean, that can be described in the following periods: the long twentieth century that goes until 1990 characterized by a resistance within the criticism of modernity, a period of epistemic-political transition from 1990 to 1999 and the period from the beginning of the present century to the present, called "No a la mina" and the critique of modernity. Within this geograficity the resistances are categorized in three positions: resistances in territories free of extractivism, resistances in territories in dispute and territories decapitated in resistance.
\end{abstract}

Key Words: anti-extractive resistances, territory, body, positionality, geograficity, conflict.

\section{Introducción}

Nos situamos en un contexto de territorios convulsivos, dinamizados (dinamitados) y en plena transformación por el avance del extractivismo-minero en América Latina y el Caribe. Este extractivismo nació con la implantación de regímenes coloniales después de 1492. En los 526 años de modernidad/colonialidad, siguen intactas las estructuras cognitivas y la gestión política de los minerales a pesar de la relativa independencia de los Estados latinoamericanos y caribeños que, a decir verdad, fueron los responsables de articular con mayor profundidad las narrativas coloniales constitutivas de la minería moderna como hecho del extractivismo, en tanto dimensión estructural del sociometabolismo del capital como sistema-mundo (Horacio 2015).

Cuando hablamos de minería moderna, hacemos referencia a una forma de racionalidad contenida en el relacionamiento con los minerales, es decir, los minerales están desprovistos de toda impronta cultural y política, porque son meros hechos de naturaleza no significada, o sea recurso. Desde esta perspectiva, el tipo de relacionamiento tanto con los minerales en particular y/o con la naturaleza en general, sólo es posible desde la instalación de un conjunto de jerarquías establecidas con la minería a gran escala, especialmente metalífera.

Jerarquías coloniales en tanto que implantan regímenes extractivos-mineros (Machado 2015) desvalorizando las economías de la reproducción de la vida, al instalarse en las subjetividades de los cuerpos y en las objetividades de los territorios un saber moderno en detrimento de los otros saberes, como la constitución de una subjetividad que legitime la extracción y la explotación a la vez que vacía de contenido otras subjetividades y mundos epistémicos diferentes al moderno. De igual forma, 
se sujeta políticamente las entidades territoriales y el desplazamiento de las funciones del Estado en cuanto gestor de la reproducción de la sociedad general, además del mantenimiento de la oligarquía rentista-dependiente bajo regímenes de autoridad brutalmente violentos. Paralelamente se produce una masculinización del espacio en la medida en que los territorios son feminizados, se impone el imperio de la técnica mediante el uso de megamáquinas de extracción, empleo de sopas químicas de amalgamación y con ello un riesgo creado e inducido. En ese sentido, la constitución de las jerarquías propias de la modernidad minera no es más que la disposición de los territorios (naturaleza) como de los cuerpos (fuerza de trabajo) en proceso civilizatorio colonial. Partimos de que el extractivismo en general, es el combustible energivoro que da vida a la civilización moderna-capitalistapatriarcal desde la cual se mide, se dispone y se accede a los territorios y a los cuerpos.

Si partimos desde esta perspectiva, las resistencias que son trabajadas aquí parten de una lucha contra el extractivismo en términos generales, o sea, que procuran un cambio civilizatorio, como de los regímenes extractivos-mineros que luchan por sobreguardar su existencia territorial, es decir, luchan contra la minería a gran escala que ha poblado el mundo andino-amazónico con su territorialidad del terror. Es sobre esto que se estructura el conflicto estructural de larga duración propio de la disputa por los sentidos civilizatorios concretos y no negociables. Hablamos de un conflicto irreconciliable entre los pueblos con sus modos diversos de geo-grafiar la tierra (Porto 2006) y las empresas transnacionales minerales que hacen circular el capitalismo, el colonialismo y el patriarcado. Son las resistencias contra-extractivas, entonces, las que están conteniendo la civilización de muerte propia de la modernidad/colonialidad-capitalista que cobran vital importancia ante la encrucijada de cambio civilizatorio, pues se ubican a la altura del presente siglo desde una ética propia del amor a la vida y no de un amor a la razon moderna (J. J. Bautista, ¿Qué significa pensar desde América Latina? Hacia una racionalidad transmoderna y postoccidental 2014).

En la actualidad estamos sitiados por el extractivismo dada la circulación y acumulación de capital minero en los últimos 20 años, en razón, a la reprimarización de los Estados ante el "disparo" de las economías-potencia. Es decir, el boom de las commodities (Acosta \& Brand 2018) significó una ampliación de las economías de enclaves mineros en la región, causando el deterioro de los ciclos vitales de existencia de diversas comunidades, poblando la geografía andina de conflictos socioambientales. Lo anterior, configuró un nuevo patrón de conflictividad (Porto Gonçalves 2006) donde múltiples grupos sociales localizados en espacios estratégicos para el capital-minero, se vean comprometidos porque el espacio de vida es convertido en recurso natural. ¿De qué formas y cómo podemos leer este nuevo patrón de conflictividad en el continente? ¿Cuáles son los retos metodológicos para tener una mirada regional de las luchas sociales contra 
la minería moderna y/o extractivismo sin perder de vista las experiencias de resistencia local?

Explica Porto Gonçalves que en "la conflictividad se revela ricas posibilidades teóricas y políticas” (Porto Gonçalves 2006, 19), es decir, el conflicto ha facilitado la oportunidad de teorizar-nos en los territorios de las comunidades cuando, en efecto, existe una preocupación por tematizar la vida, de racionalizar-nos en las sociedades imbricadas con sus espacios, pues en éste se definen, sin duda, los mundos y/o las territorialidades. El Ser y el no Ser se instaura concretamente en las luchas sociales como por ejemplo, se establece una división entre quienes son los depositarios legitimos e ilegitimos de la razón, los legales y/o los no legales, para disputarse un espacio. En ese sentido, se disputa la geografia de un pensamiento, la lucha por territorio.

Dentro de este escenario se permite "ampliar el conocimiento sobre el mundo, sobre cada situación los conflictos amplían el conocimiento de la sociedad sobre sus problemas" (Porto Gonçalves 2018, 89), pero también es el escenario de una toma de conciencia profunda, donde nos vemos con nuestras limitaciones y angustias. Es en el conflicto donde el cuerpo logra situarse con sus particularidades, reconoce sus conexiones territoriales, las dependencias ecológicas, la valorización del paisaje, los ríos, las montañas, los bosques, sus vecinos humanos y no humanos, es decir, aumenta la preocupación sobre su entorno, en definitiva, el cuerpo toma conciencia de la geografía que habita al geo-grafiarla con mayor potencia (Porto Gonçalves, 2006).

De acuerdo con lo anterior, las territorialidades cobran relevancia pues son movilizadas, de manera obligatoria, a ser más visibles en una diversidad de escenarios para revertir la creciente amenaza a las culturas dada la configuración territorial de la modernidad que consiste en abrir más espacio para transformar la organización social y espacial desde su extractivismo al imponer un orden. Ante esta "convulsión de los territorios" hay una nueva geografía que viene siendo producida por las resistencias contra-extractivas. Dicho de otro modo, la geografía ya no es un vasto espacio donde habitan cuerpos, sino que sobre ésta se realizan el acto de geo-grafiar la tierra, o como dice Porto, la geografía se vuelve verbo. Desde estos actos de geo-grafiar la tierra nos situamos y desde allí teorizamos, pensamos y actuamos. Lo que vemos con las diversas resistencias espacializadas en todo el continente es precisamente este acto de marcar las existencias en respuesta a la modernidad en crisis y agrietada (Walsh, 2016)

Ante este contexto escueto, numerosos pueblos levantan pancartas, protestan y dicen "No a la mina". Cuestionan las formas en como los gobiernos de izquierda o de derecha ${ }^{2}$ que, como

2. Es importante resaltar que, durante la primera década del presente siglo, la ola progresista, a saber, los gobiernos de Lula en Brasil, Correa en Ecuador, Evo en Bolivia, los Kirchner en Argentina, Chávez y Maduro en Venezuela, se igualaron con los gobiernos de derecha para impulsar una reordenación de los territorios y disposición de los cuerpos a la mano del extractivismo-minero en la región, sentando las bases 
dice Ramón Grosfoguel, son dos caras que igual ponen en jaque a los cuerpos en sus territorios. Al cuestionar la estructura jerarquía/racial constitutiva del extractivismo-minero, se definen posicionalidades y pensamientos que se producen al calor de las luchas por el territorio. En definitiva, los pensamientos producidos desde estos espacios tematizan el lado oscuro de la modernidad-extractiva, porque saben que lo que está en juego es la existencia de la vida comunitaria (Bautista, 2014).

Siguiendo este parecer, quisiera proponer las siguientes preguntas que guiarán esta reflexión ¿Cuál es la relación entre cuerpos y territorios para la comprensión de la geo-graficidad de las resistencias contra-extractivas? ¿Es a través de cuerpos que hablan los lugares? ¿Cuál es la cartografía o la geograficidad de estas resistencias?

\section{Metodología}

El desarrollo metodológico tuvo como énfasis el uso de cuatro observatorios latinoamericanos sobre conflictos socioambientales derivados por extractivismo-minero que fueron: McGill Research Group Investigating Canadian Mining in Latin America de Canadá, Envoronmetal Justice Atlas de España, Observatorio de Conflictos Mineros en Latinoamerica de Chile y el $\mathrm{NO}$ a la mina de Argentina. Como nos

de la derecha revanchista en la profundización de los regímenes extractivos como horizonte de la entidad "América a saquear", desde la cual mantener el poder de las oligarquías-periféricasdependientes dentro de los Estados de una sola nación, la del capital. interesa resaltar el papel de las resistencias contra el extractivismo-minero, fue categorizada a través de tres posicionalidades identificadas dependiendo de la existencia o no de los enclaves mineros de gran escala que fueron: resistencias en territorios libres de extractivismo, resistencias en territorios en disputa y territorios decapitados en resistencia. De igual manera, se propone tres temporalidades para comprender el patrón de conflictividad actual y su respectiva evolución, a saber, el largo siglo XX y critica de la modernidad (1900-1989), Transición epistémica y política de las resistencias contra-extractivas (19901999), No a la mina y critica a la modernidad (2000 a la actualidad). Finalmente, esta información es triangulada mediante una propuesta de cartografía de las resistencias donde propongo una geo-graficidad de las mismas en América Latina.

\section{Posicionalidades, cuerpos y territorios}

Sin lugar a dudas el cuerpo es una categoría desde la cual podemos romper el mito de la modernidad que, además de ser un cuerpo anotómico que responde a las necesidades primarias de comer, respirar, beber y sentir, en tanto que la lucha por el territorio tiene que ver con mantener determinadas anatomías en el espacio, también es una corporalidad que habla y enuncia desde una posicionalidad crítica que ha experimentado el lado oscuro de la modernidad. Es decir, de habitantes en concreto cuya experiencia relatan la colonialidad que la modernidad-minera ha intentado encubrir. 
Cuando situamos el conocimiento, éste se vuelve corpóreo, es decir, la epistemología tiene un color, una sexualidad, una ontología, un lugar desde el cual surge y se difunde. Quiere decir, que la forma en como pensamos está mediada por el espacio-tiempo, en el lugar donde habitamos que impacta nuestra experiencia. Dice Juan José Bautista (2018) que la razón tiene color de piel y su propia especificidad. Así, el conocimiento no está por fuera de las condiciones históricas para que se piense como si estuviera por fuera del espacio-tiempo. Estas ideas han sido ampliamente abordadas por las feministas y los estudios etnos/raciales en diversos espacios de América, que en buena medida nos recuerdan que "siempre pensamos desde un lugar en particular en las estructuras de poder" (Grosfoguel, 2006, 21). Según esto, tanto en los contextos de extracciónminera como en aquellos donde no ha sido posible instalación de los enclaves mineros se producen conocimientos desde esa realidad específica que alimentan el que hacer de la resistencia. De allí, que todo conocimiento crítico por antonomasia sea situado, siempre nace al calor de las revoluciones y luchas. Boaventura de Sousa nombra este proceso como las epistemologias del Sur. Algunas feministas negras lo nombran como epistemologias afrocentricas y las comunidades indígenas como epistemologías andinas-amazónicas. Muchos autores desde la perspectiva decolonial, a saber, Dussel, Mignolo, Fanon entre otros, hablan de corpopolítica del conocimiento o geopolítica del conocimiento.
Lo anterior quiere decir que el sujeto de la resistencia no encubre su etnicidad, ni su clase, ni su genero (como si lo oculta el Ser imperial-modernoextractivo), antepone sobre todo su cuerpo diferente como la coordenada y ubicación tanto epistémica como política, conectada con las condiciones realmente existentes de su territorio, o sea su materialidad. Es decir, dichas luchas están conectadas con el mantenimiento de la vida de esos cuerpos que, a través del trabajo, permita la reproducción de su vida.

Cuando la crítica parte del cuerpo oprimido y humillado, vemos una radicalidad que pretender acabar con las condiciones de posibilidad de las multiples opresiones producidas por la modernidad, porque no es una crítica que surja dentro del sistema moderno sino de las consecuencias que dicho sistema intenta ocultar, silenciar y borrar. Es decir, las consecuencias como la contaminación de los rios y valles, la destrucción de la agricultura, el despojo de los medios de subsistencia y el racismo, no están desligadas de la experiencia humana, por tanto de los cuerpos que se reproducen y habitan en los espacios afectados por dichas consecuencias.

La posicionalidad generada allí no es un particularismo, sino el conocimiento crítico que se produce para entender la universalidad del lado oscuro de la modernidad que es la destrucción. Conocimientos estos que han permitido a los cuerpos liberarse por la pasión de vivir a pesar de los sufrimientos y de la perversidad. Frantz Fanón ya había planteado que "el colonizado está 
dominado, pero no domesticado. Está inferiorizado pero no convencido de su inferioridad" (Franzt Fanon, 1961, 47). En esa misma línea, Paulo Freire (1970) había sentenciado que si bien estamos cruzados por ciertas relaciones de poder que nos humilla y nos aminora, no por eso estamos a disposición completa para el opresor, sino seres inconclusos por las ganas de vivir. Esto es lo que nos permite comprender que en lo mas íntimo de la experiencia de los oprimidos (cuerpos desarraigados o en proceso de desarraigamiento) habita las ganas de vivir e intentarán evitar su aniquilación. Es en ese pequeño espacio "del no convencimiento" de donde afloran las "nuevas utopias" (Grosfoguel, 2006) por la configuración de posicionalidades de poder de los cuerpos que intentarán de cualquier modo revertir la aniquilación de todas las formas de vida.

La frase emblemática de Fanón y Freire, resultan fundamentales para entender que no hay un afuera absoluto del sistema moderno/colonial sino una relativa exterioridad y no una completa subsunción a la modernidad. Por eso, es que la liberación, como señala Dussel (1996), sólo es posible si las respuestas nacen de esos pequeños latidos de resistencia localizados en la exterioridad relativa de las epistemologías locales. $\mathrm{Si}$ bien esos pequeños espacios de existencia, de memoria y de la posibilidad de Ser han sido afectados por la modernidad, no quiere decir, como dice el mismo Dussel, que esten subsumidos e incorporados por completo. De allí, surge la oportunidad de romper los discursos que nos disminuye y nos menosprecia (Huguet, 2016). Es desde estos horizontes relativos de la exterioridad, donde subyace la potencialidad crítica de construir comunidades imaginadas, otros mundos posibles o, en palabras de Dussel, transmodernos o un mundo transmoderno pluriversal y decolonial (Mignolo 2003).

Ahora bien, el cuerpo es el referente categorial que articula la reflexión de la Naturaleza y que, Karl Marx, hace 150 años ya había teorizado. Es fundamental subrayar que este autor en los Manuscritos: Economía y Filosofía (1844) describía que el pensamiento sobre lo real es un pensamiento que tematiza la naturaleza humanizada sobre sí misma y sobre el resto de la naturaleza, porque por fuera de ella no es nada.

"Que el hombre vive de la naturaleza quiere decir que la naturaleza es su cuerpo, con el cual ha de mantenerse en proceso continuo para no morir. Que la vida física y espiritual del hombre está ligada con la naturaleza no tiene otro sentido que el de que la naturaleza está ligada consigo misma, pues el hombre es una parte de la naturaleza" (Karl Marx, 1980, 111).

Tornarnos cuerpo, es decir, tener conciencia de que somos Naturaleza es darle lugar a un sinnúmero de significados sobre la vida por fuera de los marcos de la modernidad/colonialidad-extractiva. El cuerpo desde su trabajo está anclado-agarrado a la materialidad que produce la realidad, su vida. El cuerpo es el medio por el cual se produce lo humano viviente, es decir, el cuerpo tiene como intencionalidad prolongarse en el tiempo, prolongar su territorio o su territorialidad simbólica, por eso siempre es posicional y/o situacional. 
Es desde los cuerpos subalternizados que los espacios alternativos a la modernidad son producidos, porque en los espacios modernos estos cuerpos son anomalizados, son vistos como animales cuya única identificación es la mera presencia física o como dice Catherine Walsh (2017), la "negación del cuerpo vivido", por tanto, su epistemología, su territorialidad y su materialidad.

Esto significa que un proceso de descolonización implica mirarnos a nosotros mismos, implica mirar a nuestro cuerpo y su posicionalidad en la estructura de poder, porque de esa forma nos damos cuenta del lugar que ocupamos en el mundo, para darle cabida a otras ideas, racionalidades y valoraciones que hemos negado y nos han negado. Dice Juan José Bautista que, al elevar nuestra conciencia y lugar en el mundo, nos damos cuenta de una racionalidad que nos habita, siempre contenida en el territorio, que se despliega desde lo más profundo del Ser, una racionalidad de la vida, porque por encima del amor a la razón, está el amor a la vida. En definitiva, un amor a los cuerpos negados, o sea a los territorios y paisajes que aun guardan la posibilidad de existencia en el presente.

No se puede sustraer del pensamiento una reflexión sobre el cuerpo cuando pensamos sobre/desde el territorio, porque es desde el cuerpo que la relación colonial extractiva-minera termina, al anteponer la complejidad material de las conexiones físicas, simbólicas y políticas de los cuerpos y sus territorios de forma recíproca ante cualquier estructura de poder. Esto en buena medida está circunscrito a las resistencias en territorios libres de extractivismo, donde no solamente se defiende el territorio, sino que la defensa se amplía a niveles de racionalidad. Como dice Vilma Almendra, "la tierra para la gente no es suficiente, se necesita gente para la tierra" (Almendra 2016). Frantz Fanón lo explica mejor "Mediante un esfuerzo de reconquista de sí y de despojamiento, por una tensión permanente de su libertad, los hombres pueden crear las condiciones de existencia ideales de un mundo humano iOh, cuerpo mío, haz siempre de mí [alguien] que interroga!" (Franzt Fanón 2009, 190).

Así, la defensa del territorio es una defensa de las condiciones físicas y simbólicas de los cuerpos desarrollada en la resistencia contra la minería moderna, porque la comunidad y el territorio son indisociables, es decir, la existencia de una sociedad se realiza por medio del territorio. En palabras de Porto Gonçalves "no existe sociedad a-geográfica, así como no existe espacio geográfico a-histórico" (Porto Gonçalves, 2006, 9) "La sociedad es espacio constituida por hombres y mujeres de carne y hueso que en su materialidad corporal no pueden prescindir del agua, de la tierra, del aire y del fuego" (Porto Gonçalves, 2012, 26).

Así, toda apropiación material desde los cuerpos vivientes nos remite a una gestión como resultado de una racionalidad de la vida, que responde a los ciclos vitales de la existencia humana y no humana, es decir, cómo los grupos sociales y comunales organizan el espacio, cómo lo percibe y le otorga sentido, cómo distribuye los objetos, 
las tareas, el trabajo de sus cuerpos y las técnicas o tecnologías, en definitiva, cómo producen relaciones comunales que hace posible su existencia humana (Restrepo, 2017). Entendemos, entonces, que "el territorio es constitutivo por la sociedad en el propio proceso en que teje el conjunto de relaciones sociales y de poder" (Porto Gonçalves, 2006,13 ), es decir una forma de administrar la existencia de la comunidad.

Así toda apropiación material es a la vez simbólica y política como diría el geógrafo brasilero. De forma simple, podemos decir que el territorio en cuanto naturaleza-cuerpo-cultura permite la habitabilidad de los grupos humanos. Esto hace posible que el territorio sea una categoría política en tanto que implica pensar la cultura, por tanto, una forma de vida, una episteme contenida en el habitar humano. Al darnos cuenta de esto, confirmamos que la experiencia de las resistencias es habitada por cómo el territorio se hace mente, se hace cuerpo, se hace vida para desde allí establecer luchas por su defensa, que es a la vez defensa de su cuerpo, de su existencia. Es en ese sentido, que el cuerpo y el territorio son los marcos categoriales para comprender las posicionalidades constitutivas de las luchas por la existencia material y simbólica de las poblaciones contra el extractivismo-minero.

Resultados: por una geograficidad de las resistencias en territorios libres de extractivismo, en territorios en disputa y territorios decapitados en resistencia.

Varios autores (Zibechi, 2017), (Svampa, 2008), (Carmo Cruz, 2013) (Díaz Muñoz \& Luengo González,
2016) han planteado, en efecto, de la existencia de una cartografía de poder subyacente a los espacios de enunciación crítica, donde las territorialidades cobran relevancia política y epistémica. En ese sentido, la categoría del territorio en tanto lenguaje y espacio, se torna fundamental en las lecturas que hacemos del nuevo patrón de conflictividad contra la minería moderna. Es decir, podemos realizar una cartografía de la conflictividad si partimos de que el cuerpo siempre está situado del cual no se puede abstraer. Si esto es verdad, la cartografía de poder tiene mucho sentido cuando diversas territorialidades se disputan el espacio del pensamiento en la tierra, o sea, ésta cartografía nace de un cuerpo que está en una posición crítica de la vida, quien desarrolla una visión de su lugar en el mundo para producir discursos de interpelación (Huguet 2016).

Siguiendo este raciocinio, una temporalización de las críticas contenidas en las luchas por el territorio contra el extractivismo-minero ${ }^{3}$ serían:

El primero denominado "periodo crítico de la modernidad" es caracterizado por los derechos humanos, las revoluciones tecnológicas, luchas

3. Por periodicidad se entiende la duración de fenómenos sociales que no corresponden con siglos o décadas, sino procesos de emergencia, maduración y transformación de dicho fenómeno social. Por geograficidad entendemos el contenido espacial de un fenómeno social, es decir, sus características, narrativas, los actores y lugares donde se materializa. Esta geograficidad aplica sólo para las resistencias contra-extractivas en América Latina, existirán otras geograficidades similares o no en relación a otros procesos de resistencia. 
obreras y el sueño del progreso. Este periodo cubre el siglo XX que va hasta 1989. Durante esta periodicidad, la cantidad de resistencias contra-extractivas registradas no fueron escenarios de preocupación regional, puesto que las agendas nacionales e internacional estaban enfocadas en la coyuntura del momento como las guerras mundiales y el espectacular crecimiento económico especialmente del norte global. Sin embargo, hay que reconocer que muchas resistencias nacieron exigiéndole al Estado una mayor garantía de los derechos al trabajo y a un ambiente sano. Cabe resaltar que el inicio de este periodo es el pleno siglo XX. Sin embargo, sabemos y la historia americana nos ha enseñado, que las luchas contra el extractivismo-minero nacen con las luchas indígenas en los siglos pasados. No obstante, periodizamos este inicio de lucha desde la configuración de movimientos sociales en la década de los años 70 , teniendo como objetivo una lucha en términos de reclamos institucionales por la falta de garantías sobre las bondades de la minería moderna.

El otro periodo inicia en 1990 a raíz de las diversas resistencias indígenas y del aumento relativo de los conflictos socioambientales por minería a gran escala en la región. Es destacada la resistencia contra-minera de la comunidad en Intag, en la provincia de Imbabura en Ecuador. Fue la primera resistencia en el país que selló la salida de varias empresas transnacionales a principio de esta década. En la actualidad esta comunidad persiste, pero bajo condiciones de amenaza y amedrentamiento. Este periodo es inaugurado cuando emergen las luchas indígenas por el reconocimiento de su territorialidad ante el Estado, como el levantamiento indígena del Inti Raymi en 1990 en Ecuador, el levantamiento zapatista en 1994 en México. Además de las diversas marchas, considerando como representativa la de los pueblos indígenas del oriente boliviano denominada marcha "por el territorio y la dignidad" en 1990.

Es un periodo de transición epistémica y política donde se confronta los límites de los derechos humanos y de las luchas obreras, cuando no vasta la exigencia de los derechos y reclamos ante el Estado. Se descubre la necesidad de un cambio civilizatorio dado los cuestionamientos a las promesas de la modernidad de llevar desarrollo y progreso en la región, traducidas en emprendimientos mineros encubriendo los despojos de pueblos y contaminación de los ecosistemas. Esto se demuestra en los cambios de sentido crítico de varios movimientos antimineros, a saber, Movimento dos Atingidos por Barragens y Coordinadora Nacional de Comunidades Afectadas por la Minería en el Perú que transformaron sus críticas pautadas en las garantías de los derechos y del fortalecimiento del Estado en las décadas pasadas, hacia una crítica a la modernidad, es decir, contra el capitalismo, el colonialismo y el patriarcado (masculinización de los espacios). Este periodo va hasta 1999 cuando se realiza la primera consulta popular contra la minería moderna en América Latina, en Tambogrande-Perú y considerando la de CochabambaBolivia. Cabe resaltar la aplicación de las políticas neoliberales en las leyes mineras nacionales en Argentina, en 
Brasil, en Colombia y Centro América enfocadas en la apertura para los capitales transnacionales durante esta década.

La ampliación de las resistencias iniciadas en Tambogrande, Perú y en Esquel, Argentina, además del aumento de la conflictividad contra la minería que inicia en el año 2000 , se da en un contexto donde los mercados mundiales de los minerales reaccionan positivamente ante la aceleración económica de los países asiáticos, cuyas secuelas significó un aumento de los emprendimientos mineros en la región, inaugurando un periodo de asesinatos selectivos y de expropiación masiva de cuerpos y de sus territorios. Ante este contexto, las resistencias actuales han optado por una crítica radical al extractivismo-minero, dados los aprendizajes de las resistencias en las décadas pasadas que permitieron derrumbar el mito del desarrollo. Las memorias de las comunidades en resistencias han sido las responsables de poner en evidencia las falacias de la modernidad minera porque saben que, "si aquí pasó, allá también pasará, si allá mintieron, aquí y hoy también lo harán”. El conocimiento de estas falacias se hace memoria en los territorios y cuerpos para confrontar al Estado y a las transnacionales. También se radicalizan las narrativas de que los minerales son cuestiones de la nación y no de los pueblos. Es en esta etapa en la que nos encontramos en la actualidad.

También es un periodo donde las resistencias contra la minería moderna recurren al "buen vivir" como horizonte de racionalidad de la vida, pues ya es imposible ocultar las consecuencias de la minería transnacional. Es decir, las resistencias han aprendido de la historia latinoamericana, han agenciado la forma en cómo y bajo qué presupuesto la Abya Yala fue sustituida por la "entidad América" y con qué propósitos. Esta fase es marcada por procesos de desprendimientos epistémicos iniciados desde abajo. Quiere decir que la geo-graficidad actual de las resistencias tienen esta característica transcendental de liberar los espacios de las narrativas modernas de la minería, hacia la creación de mundos y radicalización de los existentes. De acuerdo con lo anterior, las críticas se van adaptando a la geo-graficidad de las resistencias quienes desarrollan marcos categoriales que permitan orientar su quehacer político y en la producción del conocimiento. Podemos decir y resumiendo este apartado que, como dice Juan José Bautista

"Ahora el tiempo es «nuestro tiempo», porque ahora el tiempo histórico y el tiempo de la política ya no acontecen de modo impersonal ante la vista impávida de los pueblos, sino que el pueblo es quien se apodera de los acontecimientos, porque ya no es objeto del tiempo impersonal de los modernos, sino que se está constituyendo en sujeto y actor de su propio destino, de su propio tiempo histórico" (Juan José Bautista, 2014, 240).

Esta periodización crítica de las luchas contra-mineras, es cruzada por tres tipos de resistencia que ha configurado una posicionalidad dependiendo del estado en que se encuentre el territorio frente a la minería moderna. 
1. Resistencias en territorios libres de extractivismo donde pueblos consiguieron cancelar los proyectos extractivos y a la vez que se radicalizan los proyectos y horizontes de vida no moderna. Estos procesos aún se mantienen con diferentes niveles e intensidades en tanto que la valoración económica de sus territorios aún persiste, esperando el momento adecuado por parte de las empresas y de los Estados para extraer el mineral de modo que el relevo generacional vaya cambiando de percepción, en esa continua imaginación ahistórica de la naturaleza del sujeto conquistador. El actor que más predomina en este tipo de conflicto es el cuerpo comunitario que ha logrado construir un proceso de años en sus luchas territoriales. Se dice que mientras el mineral exista en la montaña, la amenaza es latente y puede ser manifiesta si la resistencia disminuye. Ejemplo de este tipo de conflicto, es el movimiento del $\mathrm{NO}$ a la mina en la ciudad Esquel que, a pesar de las limitaciones en sus 15 años de resistencia en la Patagonia Argentina, está creando y produciendo otras conciencias, otras maneras de percibir el territorio a la vez que fortalecen las economías alternativas. En otras resistencias están potenciando la capacidad de la agroecología como mundo de vida.

2. Resistencias en territorios en disputa son aquellas donde ha llegado el discurso extractivo-minero. En este contexto son medidas las relaciones de poder entre imaginarios y representaciones con mayor contrariedad entre comunidades y empresas-mineras y el Estado. No se sabe aún en qué desencadenará el conflicto ambiental. Las comunidades y/o sociedades en movimiento (Zibechi, 2017) ajustan sus tácticas sociales para ejercer la resistencia con los recursos disponibles donde la información, el saber y las formas de organización juegan un papel fundamental. Ejemplo, de este caso es el conflicto desencadenado por la entrega de varios títulos mineros a la empresa Anglo Gold Ashanti en la región del suroeste del Departamento de Antioquia en Colombia, donde la empresa minera desarrolla exploraciones en el área denominada Cinturón de Oro de Colombia que agrupa a varias comunidades. Mientras avanza este proceso de exploración y prospección, las comunidades fortalecen sus capacidades técnicas, pedagógicas y de conocimiento sobre el territorio a través de escuelas, capacitaciones, incidencias políticas para el desarrollo de acuerdos municipales contra la minería, reconocimiento de las condiciones ambientales y de las leyes sobre participación ciudadana y minera, esto le ha permitido construir una resistencia y plantear la categoría de "territorio de vida" para defenderlo.

3. Los territorios decapitados en resistencia son desarrollados ya en contextos de extracción-minera a cielo abierto o subterránea a gran escala, que buscan rearticular, resignificar e incluso reconocer los errores de aceptar los discursos del desarrollo sacrificial, además del espejismo 
de la riqueza ilimitada como el gran engaño moderno. Tal resistencia está encaminada a demandar a las empresas e instituciones del Estado por los incumplimientos de los beneficios prometidos como la construcción de infraestructura básica, colegios, vías, puestos de salud e incluso hasta kits escolares. Paralelamente, esta resistencia propende por mejorar procedimientos de impacto ambiental para evitar desastres como los que ya se conocen por toda América Latina y el Caribe. Hay una vigilancia minuciosa por parte de las comunidades de todo el proceso extractivo-minero para denunciar alguna eventualidad, corrupción y contaminación. Asimismo, dentro de este grupo de resistencias también se busca paralizar, suspender y cancelar los emprendimientos extractivos dados los diversos desastres y de la resignificación del discurso de muerte que encubre la "minería responsable"4.

4. El discurso de muerte que encubre la "minería responsable", hace referencia al mito sacrificial que la modernidad ha desarrollado con el propósito de articular los territorios a los circuitos de la acumulación y circulación del capital, además de la constitución de jerarquías coloniales que desplaza, despoja y desterritorializa mundos de vida que no van en consonancia con la subjetividad y/o positividad de la minería a gran escala. La minería que está cruzada por la modernidad como proyecto de la subjetividad de la burguesía (Bautista 2018), necesita eliminar toda racionalidad de vida comunitaria para disponer de las fuerzas vitales de energía acumuladas por siglos, incluyendo el trabajo humano. La minería moderna está cubierta, como dice Franz Hinkelammert (1977), por una racionalidad irracional que ante su paso destruye absolutamente todo. El discurso de muerte es la desacralidad de la vida porque destruye su misterio. "La tierra es de quien la trabaja con las manos porque están
También hay una fuerte tensión contra la minería ilegal.

La mayoría de las luchas sociales contra el extractivismo-minero en la región están en esta categoría. Por ejemplo, en la localidad de La Unión, Honduras, la comunidad campesina de Azacualpa realizó manifestaciones y marchas contra la empresa Minosa por el incumplimiento de los acuerdos de construcción de viviendas, a modo de compensación por el impacto ambiental en sus territorios en el 2016. Las comunidades del municipio de Miramar en Costa Rica, alertaron sobre la inminente ruptura del relave de la mina Bellavista, cuya consecuencia sería la contaminación de las aguas subterráneas y superficiales. Pese a los antecedentes de suspensión de la extracción en el 2005 y 2007 donde se comprobó la existencia de la contaminación, aún continúa operando la minera. En Perú, las comunidades indígenas del distrito de Orcopampa realizaron una marcha en el 2014 para exigir a las autoridades la inmediata intervención por el impacto ambiental, producto del derrame de cianuro de la empresa Orcopampa que contaminó cinco hectáreas de pastizales naturales. En Chile, la comunidad de Yulahuen, realizó una marcha para detener la mina que hay en sus territorios. La marcha en el 2013 se da por

conectadas con el misterio de la vida", nos dice Bautista (2018). Con el extractivismo-minero no solamente vemos expropiación eco-biopolítica (Machado 2016) de las fuentes vitales como el agua y la tierra, sino la destrucción literalmente del trabajo reproductivo. Según esto la mineria responsable no es mas que una falacia que encubre el discurso de muerte constitutivo de la modernidad/colonialidad. 
el incumplimiento de las autoridades porque no ha llegado el desarrollo económico y social. En Cajamarca, Perú, la mina Yanacocha ampliará sus dominios con la explotación en territorios indígenas usando las aguas de la laguna Conga y las comunidades se resisten a esa ampliación. En Bolivia la Coordinadora en Defensa del Río Desaguadero, Lagos Uru Uru y Poopó (Coridup) que aglutinan alrededor de 80 comunidades, han trabajado para mejorar las condiciones ambientales, quieren que las empresas y el Estado cumplan con responsabilidad los pactos y compensaciones ambientales a la vez que se desconfía de sus acciones. Así, hay millares de casos en América Latina y el Caribe.

Las resistencias mencionadas en los anteriores puntos recurren con mayor fuerza o no a las narrativas críticas de los bienes comunes y naturales, otras recurren al buen vivir/Sumak Kawsay o Qamaña, otras a los derechos humanos ambientales y otras al ecofeminismo ${ }^{5}$. En consecuencia, desde estas posicionalidades, las resistencias encuentran varias maneras de reproducir discursos contra la minería para agrietarla, pero también, les permite descubrir/descolonizar los imaginarios del extractivismominero de manera diferenciada. No

5. Maristella Svampa denomina este proceso como giro ecoterritorial como una de las características de los movimientos ambientales actuales, que presenta un "cruce innovador entre matriz indígena-comunitario y el discurso ambientalista” (Svampa 2011, 12). Ahora bien, lo más correcto es hablar de giro territorial porque el territorio en sí implica la dimensión físicanatural-ecológica. Es decir, el territorio nos remite a una relación entre la cultura-naturaleza de toda sociedad. existe una regularidad en todas las resistencias sobre los discursos, pero si se evidencia que múltiples resistencias inician con un discurso de los derechos humanos y "críticos de la modernidad" como la justicia ambiental o de derechos humanos y transitan hacia otras formas de producir la "crítica a la modernidad” (Rodríguez Reyes, 2017), recurriendo a formas ontológicas no modernas como el buen vivir. De allí, la potencialidad de la "descolonización epistémica" de/en las resistencias contra la minería moderna.

Es importante aclarar que las resistencias contra el extractivismo-minero son dinámicas, cambiantes y también son temporales dependiendo de las relaciones de poder, es decir, el conflicto permanece, pero las resistencias cambian de posicionalidades a la vez que aumentan su experiencia crítica. De acuerdo con esto, una resistencia en "territorios en disputa" puede pasar a "territorios libres de extractivismo", dado las condiciones de posibilidad y de las capacidades que permite el contexto sociopolítico. Sin embargo, puede terminar en "territorios decapitados" por los cambios en la política institucional a través de la legislación ambiental-minera, la brutalidad con que se construye un régimen de expropiación, corrupción, lideres comprados o nombrados por los gobiernos que negocian con transnacionales, firman concesiones y permisos a espaldas de las comunidad, el financiamiento de grupos o agentes internos para boicotear la resistencias, cambios de las actuaciones de los gobiernos, por el aumento de los precios de las materias primas en el mercado mundial. Esta 
categorización debe ser entendida de manera abierta. No hay recetas sino condiciones de como el cuerpo asume cada experiencia en estos contextos de conflictividad, que le permite cambiar su crítica y su discurso.

En las tres categorías mencionadas las territorialidades son diferentes, algunas son más reaccionarias y contestarias, otras demandan ajustes al modelo institucional del desarrollo, otras procuran movilizar la ciudadanía para detener las actividades extractivas, en otras adoptan las ideas ontológicas de pueblos indígenas, afrodescendientes o identidades campesinas o son las mismas comunidades en su diversidad cultural que resisten. A continuación, son ilustradas tres cartografías de acuerdo a los criterios descritos anteriormente ${ }^{6}$.

Los datos triangulados de cuatro observatorios especializados en el seguimiento a los diversos conflictos socioambientales en ALyC, a saber, McGill Research Group Investigating Canadian Mining in Latin America, Envoronmetal Justice Atlas, Observatorio de Conflictos Mineros en Latinoamérica y el NO a la mina, confirman que, a partir del inicio del XXI, la cantidad de conflictos generados por minería a gran escala crecieron significativamente en comparación con las décadas del siglo pasado. Mirado desde la temporalidad moderna, en el siglo XX fueron contabilizados 68 conflictos, lo que va del siglo

6. Las imágenes de la simbología de los mapas fueron tomadas de internet para resaltar los tipos de resistencias.
XXI son contados $268^{7}$. En tan sólo 17 años hubo un aumento en 394\%.

Los países con mayor número de conflictos socioambientales relacionados con la actividad extractiva-minera son Perú (60), Colombia (58), Chile (43), México (40), Argentina (35), Brasil (26), Bolivia (12), Guatemala (16), Ecuador (10), Panamá (6), Costa Rica (5), República Dominicana (5), Honduras (5), Nicaragua (4), Venezuela (4), Salvador (4), Uruguay (3), Jamaica (1), Paraguay (1), Trinidad y Tobago (1) y Guayana (1). Cabe destacar que la mayoría de los conflictos socioambientales registrados, corresponden a la primera década del presente siglo que coincide con los gobiernos progresistas en Ecuador, Argentina, Brasil, Uruguay, Nicaragua, Venezuela, que acentuaron la estructura colonial del extractivismo-minero ${ }^{8}$.

De acuerdo con la temporalidad crítica de los discursos de las resistencias y de la configuración de la posicionalidad de las resistencias se obtuvieron los siguientes resultados en total:

7. Los conflictos socioambientales por minería cuantificados aquí fueron sumatorias usando los observatorios de carácter regional. No se incluyen, los observatorios nacionales existentes donde aparecen otros conflictos. Por ejemplo, según el observatorio de conflictos sociales en Perú, vinculado a la Defensoría del Pueblo, identificó en el 2015 un total de 211 conflictos sociales asociados a la minería. En Colombia el trabajo realizado por Mario Pérez-Rincón (2016) caracteriza las injusticias ambientales en Colombia, identificando 115 casos de conflictos socio-ambientales. En Brasil, el Estado de Minas Gerais cuenta con un observatorio de conflictos ambientales que registran más de 100 casos de conflictos.

8. Ver Gudynas (2009), Machado (2010, 2013). 


\begin{tabular}{|c|c|c|c|c|c|}
\hline \multicolumn{2}{|c|}{$\begin{array}{c}\text { Largo siglo XX y crítica } \\
\text { de la modernidad } \\
\text { (1900-1989) }\end{array}$} & $\begin{array}{c}\text { Transición epistémica y } \\
\text { política de las resisten- } \\
\text { cias contra-extractivas } \\
(1990-1999)\end{array}$ & \multicolumn{2}{|c|}{$\begin{array}{c}\text { No a la mina y crítica a } \\
\text { la modernidad (2000 a la } \\
\text { actualidad) }\end{array}$} \\
\hline $\begin{array}{c}\text { resistencias en te- } \\
\text { rritorios libres de } \\
\text { extractivismo }\end{array}$ & 3 & $\begin{array}{c}\text { resistencias en te- } \\
\text { rritorios libres de } \\
\text { extractivismo }\end{array}$ & 4 & $\begin{array}{c}\text { resistencias en te- } \\
\text { rritorios libres de } \\
\text { extractivismo }\end{array}$ & 37 \\
\hline $\begin{array}{c}\text { resistencias en } \\
\text { territorios en dis- } \\
\text { puta }\end{array}$ & 0 & $\begin{array}{c}\text { resistencias en } \\
\text { territorios en dis- } \\
\text { puta }\end{array}$ & 2 & $\begin{array}{c}\text { resistencias en } \\
\text { territorios en dis- } \\
\text { puta }\end{array}$ & 72 \\
\hline $\begin{array}{c}\text { territorios decapi- } \\
\text { tados en resisten- } \\
\text { cia }\end{array}$ & 22 & $\begin{array}{c}\text { territorios decapi- } \\
\text { tados en resisten- } \\
\text { cia }\end{array}$ & 37 & $\begin{array}{c}\text { territorios decapi- } \\
\text { tados en resisten- } \\
\text { cia }\end{array}$ & 159 \\
\hline Total & 25 & Total & 43 & Total & 268 \\
\hline
\end{tabular}

Cuadro 1: resultados de triangulación de los periodos y tipos de resistencias. Construcción propia.

Según la tendencia mostrada, podemos decir que si existen transiciones o proyectos de liberación de forma paulatina contra el extractivismo-minero, asegurando los territorios y sus economías locales por fuera de las escalas de acumulación del capital propias de la minería transnacional.

Durante la primera década del siglo XXI se observa un crecimiento de conflictos ambientales en territorios decapitados. Dentro de los conflictos socioambientales predominan los "territorios decapitados en resistencias" en tanto que las multinacionales lograron construir los enclaves e imponer sus regímenes extractivos (Machado, 2015) apoyados por los gobiernos de la región. Alberto Acosta denomina esta etapa como neoextractivismo (Acosta, 2012). Pero también se evidencia el aumento de "resistencias de territorios en disputa" que obedece a la inminente llegada de las empresas mineras, cuyos pueblos no aceptan y tal vez no dejarán pasar las industrias como sucedía en las décadas pasadas, donde el desarrollo minero se enmascaró con la promesa de una vida mejor promovida por el neoliberalismo. En la actualidad, esta promesa ha sido y está siendo desmontada y desenmascarada, dada la historia latinoamericana ya hecha memoria en los pueblos, al poner en evidencia los límites de la modernidad/colonialidad en los espacios cuyo futuro fue asignado como lugar de conquista y de saqueo. Es decir, hay alguna o plena conciencia del neocolonialismo que supone la minería moderna a la cual las sociedades en movimiento no están dispuestas a aceptar en sus territorios (Zibechi, 2017), cuya misión descolonizadora es construir territorios libres de extractivismo-minero. 


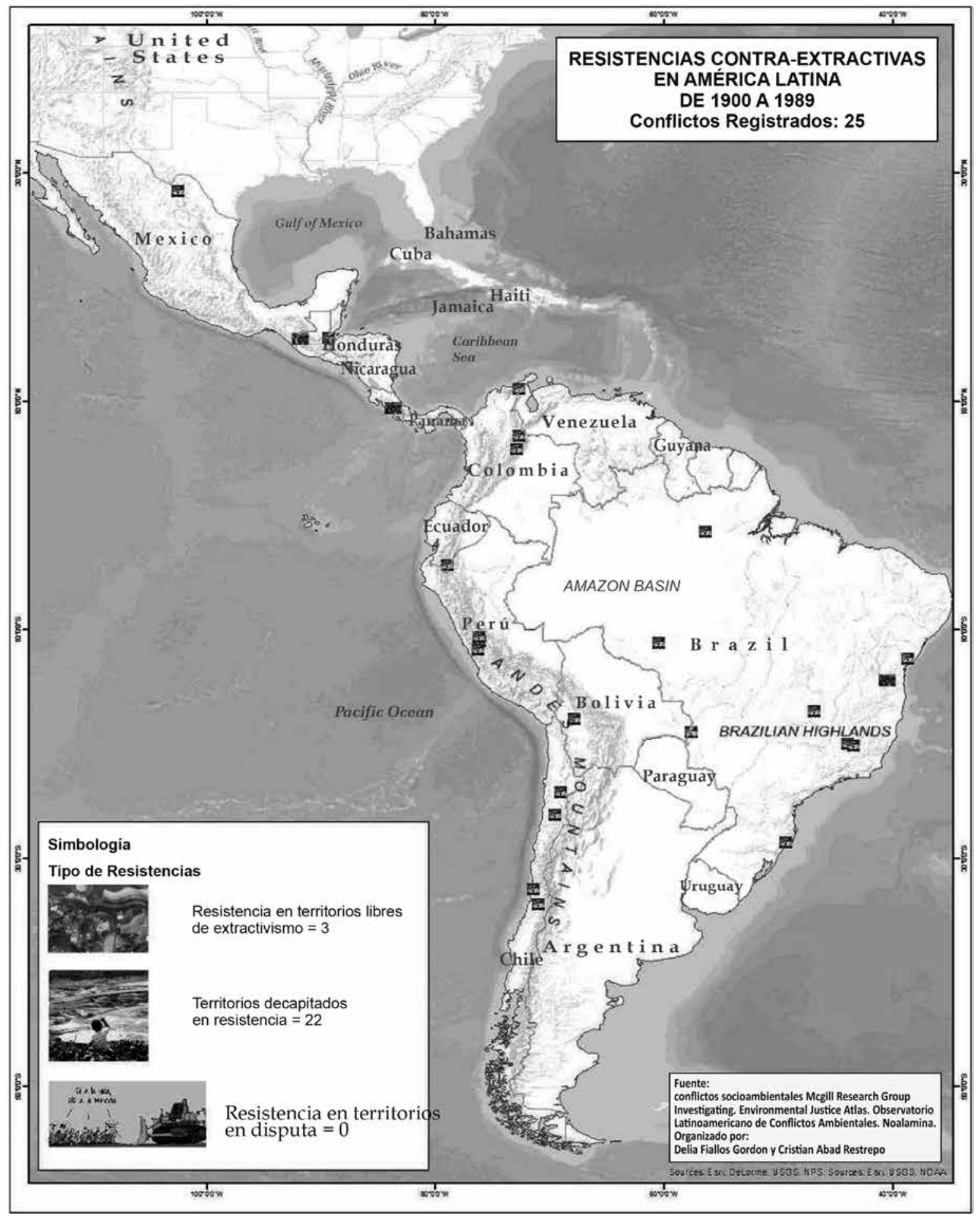

Figura 1. Resistencias contra-extractivas en América Latina y el Caribe en el largo siglo XX y crítica de la modernidad. 


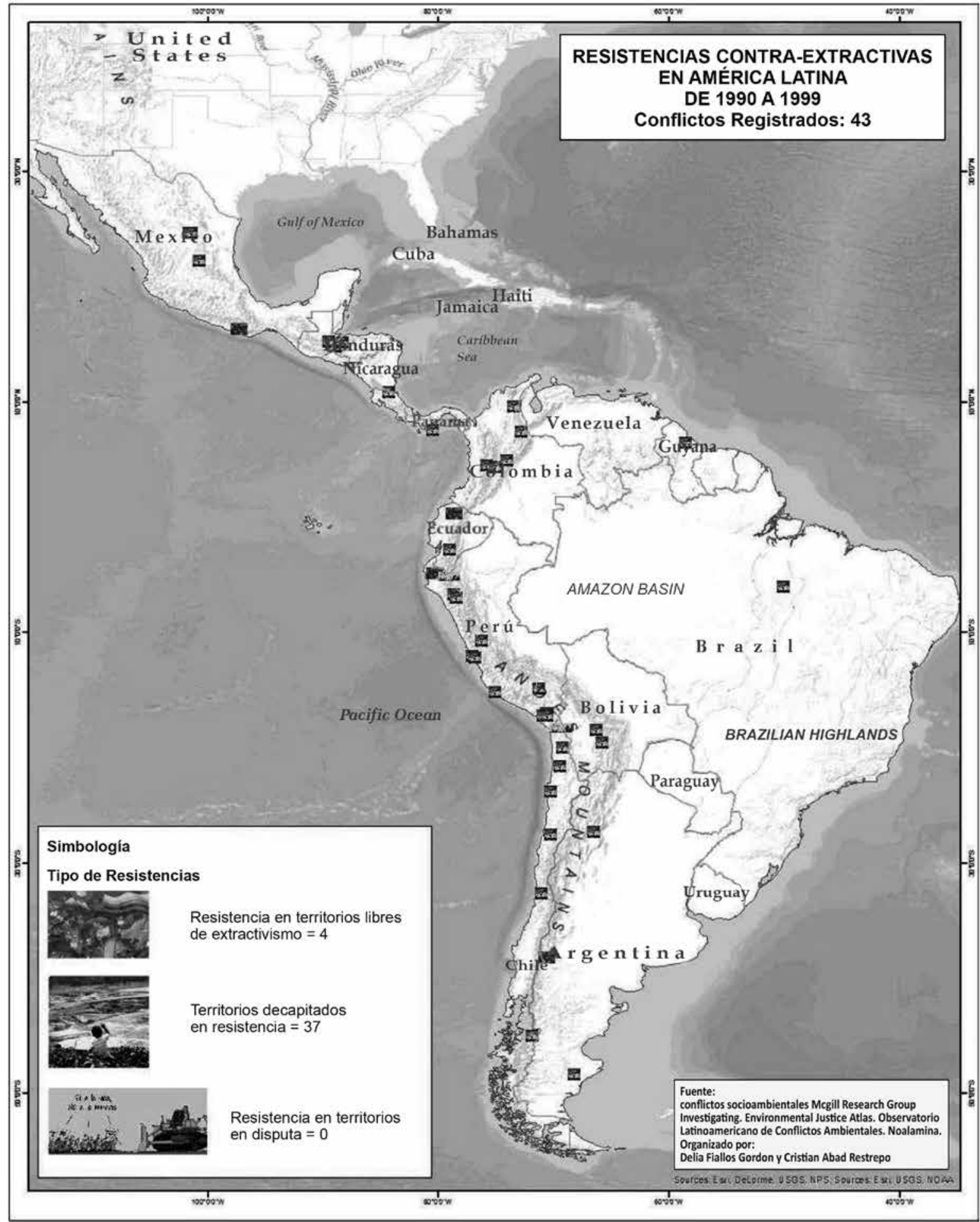

Figura 2. Resistencias contra-extractivas en América Latina en la época de transición epistémica y política de las luchas por el territorio. 


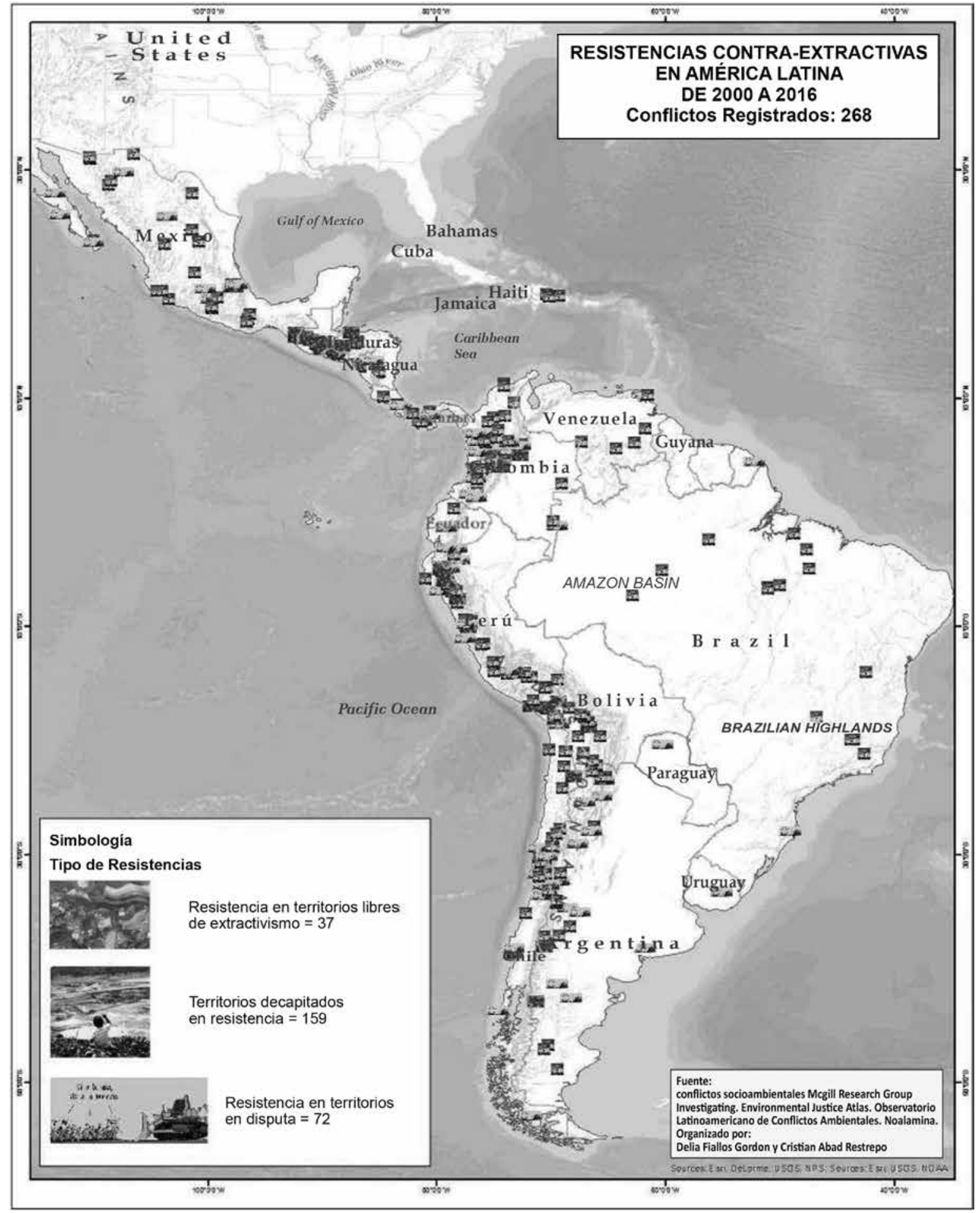

Figura 3. Resistencias contra-extractivas en América Latina en la época del No a la mina y crítica a la modernidad. 


\section{Conclusiones}

El análisis del patrón de conflictividad contra el extractivismo-minero en América Latina y el Caribe nos invita a desarrollar creativamente formas metodológicas para leer los cambios y transformaciones en el espacio-tiempo. Es decir, tener la capacidad de conceptualizar el conjunto de eventos que suceden dentro de un espacio, sus características, sus actores y sus complejidades sin ignorar su temporalidad, su duración. Propongo esta forma de leer el espacio-tiempo de las resistencias contra-extractivas para comprender la etapa en que nos encontramos, donde coexisten múltiples y tipos de resistencias a la vez, pero concientes de la necesidad de ampliar "los territorios libres de extractivismo-minero" desde nuestra resistencia epistémica y política. En definitiva, no podemos pensar en un futuro abierto si no intentamos ampliar cada vez más estos territorios por toda la región, porque el modelo que promete el desarrollo sólo ha generado "territorios decapitados" (despojo, muertes humanas y destrucción de la Naturaleza) y, los que están en proceso de disputa, sólo han experimentado el asesinato, la amenaza, el descrédito social y un futuro que compromete la existencia de los cuerpos y sus territorios. Sin embargo, este patrón de conflictividad se revela por politizar el territorio como categoría fundamental en las actuales luchas por la vida, por el agua y por el cuerpo. Es a través de esta conflictividad que podemos ver los lugares de esperanza, la descolonización y desprendimiento de los espacios de la modernidad, no es por acaso que las resistencias usen la categoría "te- rritorios de vida" para contraponerse a la "civilización de muerte" que llega por vía del extractivismo-minero. En ese sentido, es en los "territorios en disputa" donde se definen a futuro los "territorios libres de extractivismo" o "territorios decapitados en resistencia".

Ahora bien, es transcendental saber cómo se van definiendo los territorios en disputa de aquí para adelante, en qué lugares y porqué se inclina la balanza, sea para criticar con mayor potencia los territorios decapitados, o ya sea para tematizar lo posible, los mundos existentes que nos permita avanzar hacia una democracia ecológica ${ }^{9}$ como nos recuerda Vandana Shiva (2003) o post-extractivista al decir de Eduardo Gudynas (2011) y Alberto Acosta (Acosta e Brand 2018), para entender mejor lo pluriversal como horizonte posible en un mundo donde quepan

9. La democracia ecológica tiene como sentido que los pueblos sean los gestores de su propio desarrollo acorde y/o conforme a sus culturas en materia de aprovechar o no los minerales. Es decir, que gestionen su propio proceso metabólico de vida. Esto implica una radicalización de la democracia que no es política en el sentido moderno, sino en el más crítico y sentido de radicalizar la pluralidad de formas de vida de las comunidades, exigiendo y desarrollando desde las resistencias cambios civilizatorios, es decir, un cambio en las subjetividades que objetivizan el territorio como objeto de saqueo hacia otras subjetividades que permita la reproducción política y diferencia de vida. Entonces, la democracia ecológica implica un cambio en el patrón de la toma de decisiones en consonancia con las realidades territoriales poniendo en jaque que los minerales no son asunto de la nación, o sea, de una nación blanca, moderna y patriarcal, sino que los minerales deben estar orientados de acuerdo a los horizontes de sentido de los pueblos territorializados y arraigados a la tierra. Es necesario ante la crisis civilizatoria pensarlo así. 
muchos mundos, como nos lo subraya el movimiento zapatista en México.

Es fundamental subrayar que esta geograficidad de las resistencias antimineras sólo ha sido posible por los sujetos que ponen su cuerpo como coordenada de lucha, es decir, el cuidado de su territorio implica el acto más revolucionario, pues envuelve la liberación de la especie humana de una civilización moderna que se hizo a costa de deshacer a pedazos a los cuerpos y territorios por siglos. De allí, que la liberación sea promovida, como explica Juan José Bautista de un pensar/hacer latinoamericano desde el cual nazca la crítica, es decir, otras ontologías cercanas a la Naturaleza a través del trabajo. Visibilizar los mundos existentes y aprender de ellos permitirá adecuarnos a los modos de vida necesarios para el siglo XXI. ¿Quiénes son los cuerpos protagónicos en los territorios libres de extractivismo? ¿Qué sucede dentro de estos espacios y cómo se gestionan? ¿Cómo se vive la organización comunitaria al interior de estos territorios? Son preguntas para ampliar el marco geográfico de las luchas contra el extractivismo-minero en América Latina y el Caribe. 


\section{BIBLIOGRAFÍA}

Acosta, A. (2012). "Extractivismo y neoextractivismo: dos caras de la misma maldición". Ecoportal, 25 de julio.

Acosta, A. y Brand, U. (2018). Salidas del laberinto capitalista. Decrecimiento y postextractivismo. Quito: Fundación Rosa Luxemburg.

Almendra, V. (2016). Extractivismo y luchas en América Latina [Video]. Ciudad de México, 19 de marzo.

Bautista, J. J. (2017). ¿Qué significa pensar desde América Latina? Hacia una racionalidad transmoderna y postoccidental. Madrid - España: Ediciones Akal, S.A.

Bautista, J. J. (2018). “De la sociedad moderna a la comunidad transmoderna. Hacia una descolonización del marxismo contemporáneo". Em Pensar Distinto, Pensar Descolonial, por Pensar Distinto, 1-9.

Bautista, J. J. (2018). El espíritu de la revolución del siglo XXI .2.19 de noviembre. https://www.youtube.com/ watch?v=phgSTWc310w (acesso em 2018).

Carmo Cruz, V. do (2013). “Das Lutas por Redistribuição de Terra às Lutas pelo Reconhecimento de Territórios: Uma gramática das lutas sociais". Em Cartografia social, terra y território, por Henri Acselrad, 119-176. Río de Janeiro: IPPUR/UFRJ.

Díaz Muñoz, G. y Luengo González, E. (2016). Los movimientos sociales: Hacia otros mundos posibles. Bogotá: Desde Abajo.

Dussel, E. (1996). Filosofía de la liberación. Bogotá: Nueva América.

Escobar, A. (2014). Sentipensar con la tierra. Nuevas lecturas sobre desarrollo, territorio y diferencia. Medellín: Unaula.

Fanon, F. (1961). Os condenados da terra. Rio de Janeiro: Civilização Brasileira.

Fanon, F. (2009). Piel negra, máscaras blancas. Madrid - España: Akal S.A.

Freire, P. (1970). Pedagogía de la esperanza . Montevideo: Tierra Nueva.

Galcerán Huguet, M. (2016). La bárbara Europa. Una mirada desde el postcolonialismo y la descolonialidad. Madrid:Traficantes de Sueños.

González Casanova, P. (2003). Colonialismo interno (una redefinición). Ciudad de México: Conceptos y fenómenos fundamentales de nuestro tiempo - Unam.

Grosfoguel, R. (2006).“La descolonización de la economía política y los estudios postcoloniales:Transmodernidad, pensamiento fronterizo y colonialidad global."Tabula Rasa, n 4 (Enero-Junio): 16-46.

Hinkelammert, F. (1977). Las armas ideológicas de la muerte. San José de Costa Rica: DEl.

Machado, H. (2014). “Territorios y cuerpos en disputa: extractivismo minero y ecología política de las emociones." Intersticios. Revista Sociológica de Pensamiento Crítico, nº 8: 56-71.

Machado, H. (2015a). “Crítica de la razón progresista. Una mirada marxista sobre el extractivismo/colonialismo del siglo XXI". Actuel Marx / Intervenciones, no 19 (12 2015): 137-173.

Machado, H. (2015b). “Ecología política de los regímenes extractivistas. De reconfiguraciones imperiales y re-ex-sistencias decoloniales en nuestra América". Bajo el Volcán 15, nº 23 (septiembre-febrero): 11-51. 
Machado, H. (2016). “Sobre la Naturaleza realmente existente, la entidad'América'y los orígenes del capitaloce. Dilemas y desafios de especie." Actuel Marx / Intervenciones, nº 20 (junio): 205-230.

Mignolo, W. (2003). Historias locales/diseños globales: Colonialidad, conocimientos subalternos y pensamiento fronterizo. Madrid: Akal.

Porto Gonçalves, C. W. (2006). “A geograficidade do social: uma contribuição para o debate metodológico para os estudos de conflictos e movimentos sociais na América Latina". Revista Electronica da Associação dos Geografos Brasileiros - Seção Três Lagoas-MS, Maio: 5-26.

Porto Gonçalves, C. W. (2018). Amazonía: Encrucijada civilizatoria. Tensiones territoriales en curso. La Paz, Bolivia: Instituto para el Desarrollo Rural de Sudamérica, CIDES.

Restrepo, C. A. “La cartografia: herramienta para visibilizar territorios subalternizados.” La Estrella de Panamá, 3 de 12 de 2017.

Rodríguez Reyes, A. (2017). “Hacia una crítica a la modernidad desde Abya Yala”. FAIA 6, nº 29.

Shiva, V. (2003). Las guerras por el agua: privatización, contaminación y lucro. México: Siglo XXI.

Svampa, M. (2008). Cambio de época. Movimientos sociales y poder político. Buenos Aires: Siglo XXI.

Svampa, M. (2011).“Extractivismo neodesarrollista, gobiernos y movimientos sociales en América”. Problèmes de l'Amérique Latine, 1-27.

Walsh, C. (2016). "Interculturalidad y (de)colonialidad. Gritos, grietas y siembras desde Abya Yala". Congreso Brasileiro de Hispanistas. Brasilia.

Zibechi, R. (2017). Movimientos sociales en América Latina. El "mundo otro" en movimiento. Bogotá: Desde Abajo. 